\title{
The Effectiveness of Model's Body Size in Digital and Print Advertisements
}

\author{
Safaa Adil ${ }^{1}$, Ahmad Mostafa Abdeltawab $^{1} \&$ Danielle Lecointre-Erickson $^{2}$ \\ ${ }^{1}$ Department of Marketing \& Retailing, ESSCA School of Management, Angers, France \\ ${ }^{2}$ Université Catholique de l'Ouest, Angers, France \\ Correspondence: Ahmad Mostafa Abdeltawab, Department of Marketing \& Retailing, ESSCA School of \\ Management, Angers, France. E-mail: ahmad.adel.work@gmail.com
}

Received: May 10, $2021 \quad$ Accepted: June 15, $2021 \quad$ Online Published: June 21, 2021
doi:10.5539/ijms.v13n3p1
URL: https://doi.org/10.5539/ijms.v13n3p1

\begin{abstract}
Advertisings usually display thin bodies creating and endorsing the beauty standards of the society. Large body size models are sometimes featured in advertisings to show a more inclusive marketing communication. Previous researches have investigated consumer responses to more diverse body sizes in Beauty and Fashion industries ads. This paper aims at investigating advertisement effectiveness, for both print and digital advertisings, through consumer responses (Memorization, Aad, Ab, and Purchase Intention) to body sizes in food advertisements.
\end{abstract}

We used a mixed design study with a between group factor (Media type: Print or Digital) and a within-subject variable (body shape: large, thin or no model), via a folder test procedure. Participants were exposed to a fictive magazine to measure their responses toward advertisements featuring large size model versus thin one.

The findings reveal that "large model" advertisements are less effective compared to "thin model" advertisements for Memorization, Attitude towards Ad, and Purchasing Intention. However, participants expressed the same Attitude towards the Brand for both conditions. Moreover, hardly any significant influence of the means of exposure to ads (printed or digital) was found.

Despite the latest consumer pertinacity trends on companies to adopt diversity for social reasons; consumers, of the food industry, are still better influenced by thin models when it comes to Memorization, Aad, and PI.

Furthermore, this study offers practical and societal implications not only for the experimental design, but also for practitioners to comprehend and utilize the match - up hypothesis of body size condition needed for their marketing and advertising objectives.

Keywords: advertising, attitude toward advertisement, attitude toward brand, body, memorization, purchase intention

\section{Introduction}

Body is a special class of visual stimuli due to the wealth of information it conveys. The media, as the great source of information and reinforcement of the beauty body size ideal, have endorsed thinness as the ideal appearance. This has led advertising in mass media to only portray models representing highly idealized images of physical attractiveness (Halliwell \& Dittmar, 2004). Owen and Laurel - Seller (2000) stated that thinness was increasingly endorsed as beauty standard for women through media, and advertising thin model representations (Owen \& Laurel - Seller, 2000).

The idealized thin body in advertising establishes beyond reach and unrealistic beauty standards (Borau \& Bonnefon, 2017). These standards may be compatible with social ideals (Haboush et al., 2012) but it creates a dissonance in consumer's perception of his own body image (Monro \& Huon, 2005), provoking some psychological and behavioral disorders (Grabe et al., 2008). However, this is a social comparison method used sometimes by marketers deliberately to influence self-esteem and create a gap between the actual and ideal state of affairs in consumers, in favor to their product (Häfner, 2004). Accordingly, public health concerns encouraged the use of more diverse and natural models in advertising. Recently, some legislations (e.g., in France and the UK) have emphasized the change in mass media body image through regulations, airbrushing notification, and the reinforcement of model body size diversity (Janssen \& Paas, 2014). In the last several years, advertisers have 
started using non-idealized models in adverting (e.g., Dove's Campaign for Real Beauty), including large size models instead of the thin ideal ones.

Shoenberger et al. (2020) showed that contemporary consumers fitting more and more into a plus-size body size probably prefer advertising with plus-sized models (Shoenberger et al., 2020). Furthermore, some research defines a "relief effect" that occurs when women feel more positive about their bodies after viewing average-size models (Anschutz et al., 2009; Dittmar \& Howard, 2004). Shoenberger et al. (2020) reported that decreasing comparison between consumer and advertising model body leads to a positive advertising evaluation (Cornelis \& Peter, 2017). Antioco et al. (2012) found that using large size models in ads can increase purchase intention (Antioco et al., 2012). Also, Shoenberger et al. (2020) found that large size models generate more positive evaluation than thin ones (Shoenberger et al., 2020).

However, some studies findings suggested that large models may negatively impact advertising performance (Buunk \& Dijkstra, 2011; Hüttl \& Gierl, 2012). These contrasted empirical evidences are not reassuring advertisers that including a more diverse range of body sizes in ads is an effective and marketable alternative to the omnipresence of thin ones (Janssen \& Paas, 2014). Advertisers may be concerned about the effectiveness of displaying a large model in their advertising instead of the idealized thin model. The societal responsibility of advertising should respond to public health requirements but ensure marketing performance.

This paper aims at investigating how a model's body shape influences consumer's responses to advertising. Based on psychology and marketing literature highlighting the potential effects of body shape on observer's responses, we conducted a mixed design study using a folder test procedure for print and online ads. The findings confirm the importance of the model's body shape as a variable moderating advertising effectiveness.

\subsection{Literature Review}

\subsubsection{Body Type and Cultural Categorization}

The body image of women in advertising has become a crucial societal concern because of the potential negative impact on consumers' psychology and well-being (Borau \& Bonnefon, 2017; Hüttl \& Gierl, 2012). In the late 20th century, thinness was considered a preferred body type in the Western society (Lennon, 1992). Unilever's launch of the Dove Campaign for Real Beauty in the early 2000s reflected consumers' desire to do away with unrealistic, airbrushed, and idealistically ultra-thin female representations (Bissell \& Rask, 2010). Psychology theory explains that consumers' perception of body type attractiveness is influenced by culture. According to Festinger's (1954) Social Comparison Theory, humans strive to compare themselves to an objective standard. If there is a lack of objective standards, the object of comparison then becomes another human being (Festinger, 1954). When applied to our study, this theory would suggest that $21^{\text {st }}$ century Western consumers compare themselves more positively to fuller body types in advertising messages.

However, literature is mixed when examining the effects of model body type on affective, cognitive, and conative reactions. The omnipresence of thin models in advertising can alter women's appearance self-esteem and induce some eating disorders (Hüttl \& Gierl, 2012). Shoenberger et al. (2020) showed that contemporary consumers fitting more and more into a plus-size body size probably prefer advertising with plus-sized models (Shoenberger et al., 2020). Furthermore, some researches define a "relief effect" that occurs when women feel more positive about their bodies after viewing average-size models (Dittmar \& Howard, 2004). Shoenberger et al. (2020) reported that decreasing comparison leads to positive advertising evaluations (Cornelis \& Peter, 2017). Antioco et al. (2012) found that using large size models in ads can increase purchase intention (Antioco et al., 2012). Also, Shoenberger et al. (2020) found that large size models generate more positive attitudes than thin ones (Shoenberger et al., 2020). Anschutz et al. (2009) experimental study found that respondents recalled a significantly greater number of commercials and expressed a higher liking of target commercials in the realistic-model condition than in the thin-model; however, the study was on body-care products; not the food industry (Anschutz et al., 2009).

Other studies contradicted these findings and suggested that large models may decrease advertising performance. Buunk and Dijkstra (2011) found that less attractive models have a negative impact on Attitude toward the Product and Purchasing Intention (PI) (Buunk \& Dijkstra, 2011). In one study, good-looking fundraisers raised almost twice as much as other volunteers who were not as attractive (Solomon, 2015). Likewise, Hüttl and Gierl (2012) reported that large models decreased attitude towards the product and purchase intention for perfume (Hüttl \& Gierl, 2012).

Finally, some other studies reported a null effect of models' body size on advertising performance. Diedrichs and Lee (2011) and Halliwell and Dittmar (2004) reported that thin and larger models have the same impact on attitudes toward the brand (Halliwell \& Dittmar, 2004). 


\subsubsection{Model Size, Attitudes, Media Type and Recall}

Recent literature has sought to explain the effects of digital advertising on affective and conative responses (Stewart et al., 2018). Affective response is an important concept when analyzing advertising effects. Affect refers to "consumers' liking of a branded product" (Liu et al., 2010). Affect transfer theory (Bower, 1981; Averill, 1991) posits that affect induced from a new item will be transferred to an existing schema when the two are congruent. A schema refers to "a cognitive structure that represents knowledge about a concept or type of stimulus, including its attributes and the relations among those attributes" (Fiske \& Taylor, 1991). A schema-triggered affect occurs when a schema and its associated affect are activated (Fiske et al., 1982). When applied to the current study, this theory would suggest that positive affect associated with model size will be transferred to the product, the advertisement, and the brand.

In line with advertising literature, the Affect Transfer Hypothesis (Mitchell \& Olson, 1981) posits that affect in an advertising message will influence Attitude towards the ad (Aad), which will then influence Attitude towards the brand $(A b)$. According to the Elaboration Likelihood Model (Petty \& Cacioppo, 1986) information will be processed through either a "central route" or a "peripheral route". In this case, the case would either cognitively process the information (central-route processing) or use his/her affective reactions as a heuristic for quickly processing the information (peripheral-route processing).

In regard to memorization, recent researches have examined the effectiveness of digital and print media on cognitive processes, such as recall. Recall refers to how processed information is stored in and retrieved from memory (Gita Venkataramani Johar, 2006). Previous research suggests that individuals recall more details when exposed to print media compared to digital media. Scientists suggest this is due to disruption in attention caused by the scrolling process. In another research, the overall comprehension has been found to be more effective with print than with digital media (Trakhman et al., 2019). Delgado et al.'s (2018) meta-analysis reveals equal effects of digital and print media on cognitive processes although the effects can be moderated by reading time constraint and text genre (Delgado et al., 2018). Similarly, Ieva et al. (2018) recently found that there were no significant differences in advertising effectiveness when respondents were exposed to printed and online advertisements (Ieva et al., 2018).

Based on the literature review, this research paper extends the previous studies aforementioned and will investigate and measure if the use of a large or thin sized model body impacts advertising performance (decomposed in ad content memorization, attitude towards the ad, attitude towards the brand, and purchase intention), through two pathways: print and digital ads. The authors seek to verify the following hypotheses:

H1: Memorization of the ad will be higher in the thin model condition versus the large model condition.

H2: Memorization of the product will be higher in the thin model condition versus the large model condition.

H3: Memorization of the brand will be higher in the thin model condition versus the large model condition.

H4: Attitude towards the ad (Aad) will be higher in the thin model condition versus the large model condition.

H5: Attitude towards the brand (Ab) will be higher in the thin model condition versus the large model condition.

H6: Purchase intention (PI) will be higher in the thin model condition versus the large model condition.

\section{Research Method}

\subsection{Participants and Experimental Design}

121 young adults ( 60 women) aged 18 to 41 years $(\mathrm{M}=25.28, \mathrm{SD}=6.45)$ took part in this study. All participants were of average size considered in the host country of the study, France. They were divided into two groups, assigning each to one condition; group 1: digital ads $(\mathrm{n} 1=60,30$ women, $\mathrm{M}=24.72, \mathrm{SD}=6.410)$, or group 2: print advertisement ( $\mathrm{n} 2=61,30$ women, $\mathrm{M}=25.84, \mathrm{SD}=6.502)$. The participants, who were recruited from initial and lifelong learning programs, volunteered to take part in the study without any incentive.

\subsection{Stimuli}

We used a mixed design with a between group factor (media type: printed or digital). We conducted an experiment in which we used a folder test procedure, in a magazine form. This 12-page magazine contained three targeted advertisements for unknown brands. Their order of appearance was randomized. We implemented a within-subject design in each group featuring three conditions: a thin size model (TM), a large size model (LM), and a no model (control condition) ads. To avoid the celebrity endorsement effect (Kooli et al., 2018), we used two attractive but unknown models. All advertisements were inserted in the same position at the bottom right-hand corner of the pages. The target advertisements (separated by several pages in the magazine) concerned food products (ice cream, 
yogurt, and orange juice). To avoid effects related to prior exposure to the brand, we have selected unknown brands in the country hosting the test that might be purchased and consumed by both men and women. Two distractive ads of well-known brands were also inserted to ensure that participants would not question the presence of unknown brands only.

For each brand, three versions of the ad were created featuring unknown models (to avoid the celebrity effect), including (1) a young Caucasian thin model, or (2) a young Caucasian large model. The other advertising elements remained identical. Product/model pairing, and ads' order of appearance were randomized.

Pretest results indicated that the thin and large-size models were rated by participants as equally attractive, so that any differences post exposure could be attributed to the differing body sizes of the models. Attractiveness was assessed with a ten-point scale ( $1=$ "not at all attractive" and $10=$ "very attractive").

\subsection{Procedure}

Participants were divided into two groups. Group 1: printed magazine; Group 2: digital magazine (using iPad pro-10.5). They were asked to evaluate a travel magazine. After the participants consulted the magazine, a surprise memory task was proposed. Then participants were again exposed to the three target advertisements to complete attitude towards advertising, the brand, and purchase intention scales.

\section{Results}

\subsection{Memorization Measures}

For the digital magazine group, participants recalled more elements of the ad content in "thin model condition (TM)" (2.45 elements) than "large model condition (LM)" (1.50 elements) $(p=0.00)$. Also, they better recalled the product, and better recognized the product and the brand in the thin model condition compared to the large model one. No difference in brand recall was observed between thin and large model conditions (see Table 1).

The same tendency was observed for the print-magazine group. Participants recalled a total of 2.41 elements in LM condition and 3.93 in TM condition $(p=0.00)$. Also, they better recalled the product, recognized the brand $(p<$ 0.05 ) and recalled the brand (marginal significance $p=0.051$ ) in thin model condition compared to large model condition. No significant difference in product recognition was observed between thin and large model conditions.

Table 1. Memorization results

\begin{tabular}{|c|c|c|c|}
\hline \multirow[t]{2}{*}{ Variable } & Thin Model (TM) & Large Model (LM) & $\mathrm{P}$ (2-tailed) \\
\hline & $\mathrm{M}(\mathrm{SD})$ & \multicolumn{2}{|l|}{$\mathrm{M}(\mathrm{SD})$} \\
\hline \multicolumn{4}{|l|}{ Ad recall* } \\
\hline Print Ad & $3.93(2.45)$ & $2.41(1.90)$ & 0.000 \\
\hline Digital Ad & $2.45(2.07)$ & $1.50(1.63)$ & 0.000 \\
\hline \multicolumn{4}{|c|}{ Product recall } \\
\hline Print Ad & $0.72(0.49)$ & $0.36(0.48)$ & 0.000 \\
\hline Digital Ad & $0.47(0.53)$ & $0.17(0.45)$ & 0.000 \\
\hline \multicolumn{4}{|l|}{ Brand recall } \\
\hline Print Ad & $0.18(0.38)$ & $0.07(0.25)$ & 0.051 \\
\hline Digital Ad & $0.1(0.36)$ & $0.08(0.27)$ & 0.252 \\
\hline \multicolumn{4}{|c|}{ Product recognition } \\
\hline Print Ad & $0.75(0.43)$ & $0.70(0.46)$ & 0.471 \\
\hline Digital Ad & $0.82(0.39)$ & $0.63(0.48)$ & 0.027 \\
\hline \multicolumn{4}{|c|}{ Brand recognition } \\
\hline Print Ad & $0.49(0.50)$ & $0.26(0.44)$ & 0.005 \\
\hline Digital Ad & $0.32(0.46)$ & $0.10(0.30)$ & 0.000 \\
\hline
\end{tabular}

\subsection{Attitude Toward the Ad (Aad) Measures}

In the print ad group, participants expressed a better attitude toward the ad in thin model condition compared to large model one ( $p=0.008$, see Table 2$)$. But in the digital ad group, no difference was observed in term of Aad between the thin model and large model conditions $(p>0.05)$.

\subsection{Attitude Toward the Brand (Ab) Measures}

In both print ad and digital ad groups, there was no significant difference between the expressed attitude toward the brand in thin model or large model ads ( $p>0.05)$ 


\subsection{Purchase Intention (PI) Measures}

In the print ad group, participants expressed a higher purchase intention when exposed to thin model ad (49.98) compared to large model ad (39.52) $(p=0.016)$.

In the digital ad group, participants expressed a higher purchase intention when exposed to the TM ad (29.85) compared to the $\operatorname{LM}(18.83)(p=0.00)$

Table 2. Aad, ab, and purchase intention

\begin{tabular}{llll}
\hline Variable & Thin Model (TM) & Large Model (LM) & P (2-tailed) \\
\cline { 2 - 3 } & $\mathrm{M}(\mathrm{SD})$ & $\mathrm{M}(\mathrm{SD})$ & \\
\hline Aad & & & \\
Print Ad & $13.93(3.39)$ & $12.70(3.32)$ & 0.008 \\
\hline Digital Ad & $10.51(3.41)$ & $11.13(3.08)$ & 0.247 \\
\hline$A b$ & & & 0.407 \\
\hline Print Ad & $15.18(5.34)$ & $14.49(4.29)$ & 0.176 \\
\hline Digital Ad & $13.60(3.31)$ & $12.78(3.10)$ & 0.016 \\
\hline$P I$ & & & 0.000 \\
\hline Print Ad & $48.98(24.19)$ & $39.52(25.03)$ & \\
\hline Digital Ad & $29.85(18.57)$ & $18.83(13.61)$ & \\
\hline
\end{tabular}

\subsection{Effect of Media Type}

We can report that there was no significant interaction between the media type and ad recall in large and thin model conditions $\mathrm{F}(1,119)=2.89, p=0.091, \mathrm{r}=0.15$. There was no significant effect of media type on product recall and recognition, $\mathrm{F}(1,119)<1, \mathrm{r}=0.04$ and $\mathrm{r}=0.11$, and on brand recall and recognition, $\mathrm{F}(1,119)=0.348, \mathrm{r}=0.11$ and $\mathrm{F}(1,119)=0.017, \mathrm{r}=0.01$, indicating that in both large and thin model conditions participants memorization performance was in general the same whatever is the media type.

Another contrast looked for differences between Aad in thin model ad and large model ad comparing print ad and digital ad. There was a significant interaction effect between the media type and model body size condition, $\mathrm{F}(1$, $119)=6.65, p=0.01$. This indicates that the Aad in thin or large model ad differed according to the media type (print ad or digital ad). Print ad improved Aad in both thin model and large model conditions compared to digital ad.

There was no significant interaction between media type, and $\mathrm{Ab}$ and purchase intention in thin and large model conditions, $\mathrm{F}(1,119)<1, \mathrm{r}=0.03$ and $\mathrm{r}=0.01$.

\section{Discussion}

Recent marketing campaigns in cosmetics and fashion used larger sized models expressing new values of diversity and feminism fighting against the thinness despot. Furthermore, a stream of research highlighted the responsibility of the use of thin models in ads as a priming of many psychological problems, such as eating disorders. Thus, larger models seem to be a new avenue for fashion advertisers (Ulf Aagerup \& Edson Roberto Scharf, 2018).

The aim of this study is to examine the impact of exposure to advertisements featuring thin or large models through both digital and print media, on food advertising effectiveness. By inserting a thin model in an advertisement, we first found a better memorization of advertising content. This result was particularly interesting because it was not obtained under forced exposure conditions but using a folder test method. Thus, participant's attention was not directed towards any advertisement by the experimenter or by the used experimental procedure. In other words, in a fully charged environment containing large amounts of information, such as in magazines, the presence of a thin model in food advertising enables stronger memorization of the product. This finding is in line with previous studies that show that thin models have a positive influence on the consumer's internal response (Buunk \& Dijkstra, 2011).

Corroborating Halliwell and Dittmar (2004) study, we found that advertisements containing large model were just as effective as those containing thin model when effectiveness was measured in terms of attitude towards the brand (Halliwell \& Dittmar, 2004). Thus, larger models can be used in food advertising to fulfill some specific communication objectives like an inclusive brand statement.

However, we did not find the same effectiveness in terms of attitude towards the advertisement (specifically in 
printed ads) and purchase intention. The different product categories used in the studies suggest the difference, i.e., Halliwell and Dittmar (2004) were testing on Beauty Care products, whereas we were investigating on food products. Participants may express the same attitude towards a food brand displaying a large or thin model because it will be perceived as an inclusive brand. Nevertheless, when they evaluate a food advertisement and to express a purchase intention, they manifest a preference for the food product associated with a thin model. Hence, this can be explained through social comparison, which is people's tendency to compare themselves to ideal others. A study by Kees et al. (2008) and Roberts and Roberts (2015) showed that when women were exposed to a thin model in advertisement, they felt worse about their own bodies (Kees et al., 2008; Roberts \& Roberts, 2015). Nevertheless, they rated these ads more favorably and reported a high purchase intention for the product endorsed by the thin model.

Usually, companies prefer to use print media when their campaign objectives are related to attracting customers' attention, interest, and/or ease to understand contents or message (RAMaterics, 2020). The findings from this study show that the media type does not modulate the effect of the body shape on advertising effectiveness. However, we have found an effect of media type on the Attitude towards Ad. Marketers and advertisers seeking to enhance Aad are advised by the results to use print media.

\section{Conclusion}

Advertisers are continually searching for conditions to increase attention value of their message. Meticulously using models corresponding to the ideals of beauty considered by the society. Thinness is considered as a feature of attractiveness that positively influences consumers responses. The choice of thin models is expected to create a positive image that would objectively influence consumers to buy the product endorsed by the ideal model.

Unlike in the fashion industry, the body size effect on food advertising effectiveness is a topic that has been relatively unexplored. This gap is relevant since the fit between the model body size and the advertised product (food) is different from the one tested in the fashion and cosmetics industry. Next to a yogurt, will a larger model be seen appropriate? Or would be the thin model more effective?

"The importance of fit between the endorser and the endorsed product has been described as the "match - up hypothesis". Much "match - up hypothesis" research has focused on physical attraction" (Till \& Busler, 1998). This paper contributes to practical and societal implications for the design of advertisements, and for experimental designs; in addition to serve practitioners to comprehend and utilize the right body size condition needed for their marketing and advertising objectives. As far as the food products are concerned, our results demonstrated a significant difference between thin and large model sizes in terms of memorization, Attitude towards the Advertisement and Purchase Intention.

"In a time when there is pressure to execute socially conscious Advertising" (Shoenberger et al., 2020), brands are displaying larger models to manifest their inclusivity and responsibility. However, this is not the ideal when advertising for the purposes of memorization, Attitudes toward Ad, and Purchase Intention as presented in the results carried by this research paper. The race to satisfy the everlasting demand for companies to be socially responsible has neglected the rule of advertisement effectiveness in coherence with the Marketing objectives.

An additional contribution offered from the results of this paper is that larger models can be used in food advertising to endorse an inclusive branding strategy. Companies seeking to build or rectify a brand image through inclusive ads can do so knowing now that large models in their ads won't have a negative effect on $\mathrm{Ab}$.

\subsection{Limitations}

The limitations of this study offer opportunities for further research. First, our experiment was conducted in France; it would be interesting to replicate it in other countries with significant cultural differences. Moreover, we have only used a female body, which emerges an opportunity to investigate the influence of male body size. Finally, another future research recommendation is to test both size models in one advertisement (Michell \& Taylor, 1990).

\section{References}

Anschutz, D. J., Engels, M. E., Becker, E. S., \& Van Strien, T. (2009). The effects of TV commercials using less thin models on young women's mood body image and actual food intake. Body Image, 6(4), 270-276. https://doi.org/10.1016/j.bodyim.2009.07.007

Antioco, M., Smeesters, D., \& Le Boedec, A. (2012). Take Your Pick: Kate Moss or the Girl Next Door? The Effectiveness of Cosmetics Advertising. Journal of Advertising Research, 52(1). https://doi.org/10.2501/JAR-52-1-015-030

Averill, J. R. (1991). Emotions as episodic dispositions, cognitive schemas, and transitory social roles: Steps 
toward an integrated theory of emotion. In J. M. H. Ozer \& A. J. Stewart (Eds.), Perspectives in Personality: Self and Emotion. Jessica Kingsley Publishers.

Bissell, K., \& Rask, A. (2010). Real women on real beauty: Self-discrepancy, internalisation of the thin ideal, and perceptions of attractiveness and thinness in Dove's Campaign for Real Beauty. International Journal of Advertising, 29(4), 643-668. https://doi.org/10.2501/s0265048710201385

Borau, S., \& Bonnefon, J. (2017). The advertising performance of non-ideal female models as a function of viewers' body mass index: A moderated mediation analysis of two competing affective pathways. International Journal of Advertising, 36(3), 457-476. https://doi.org/10.1080/02650487.2015.1135773

Bower, G. H. (1981). Emotional mood and memory. American Psychology, 36(2), 129-148. https://doi.org/10.1037/0003-066X.36.2.129

Buunk, A. P., \& Dijkstra, P. (2011). Does attractiveness sell? Women's attitude toward a product as a function of model attractiveness, gender priming, and social comparison orientation. Psychol Mark, 28(9), 958-973. https://doi.org/10.1002/mar.20421

Cornelis, E., \& Peter, P. C. (2017). The real campaign: The role of authenticity in the effectiveness of advertising disclaimers in digitally enhanced images. Journal of Business Research, 77, 102-112. https://doi.org/10.1016/j.jbusres.2017.03.018

Delgado, P., Vargas, C., Ackerman, R., Salmerón, L. (2018). Don’t throw away your printed books: A meta-analysis on the effects of reading media on reading comprehension. Educational Research Review, 25, 23-38. https://doi.org/10.1016/j.edurev.2018.09.003

Diedrichs, P., \& Lee, C. (2011). Waif goodbye! Average-size female models promote positive body image and appeal to consumers. Psychol Health, 26(10), 1273-1291. https://doi.org/10.1080/08870446.2010.515308

Dittmar, H., \& Howard, S. (2004). Professional hazards? The impact of models' body size on advertising effectiveness and women's body-focused anxiety in professions that do and do not emphasize the cultural ideal of thinness. British Journal of Social Psychology, 43(4), 477-497. https://doi.org/10.1348/0144666042565407

Festinger, L. (1954). A Theory of Social Comparison Processes. Human Relations, 7(2), 117-140. https://doi.org/10.1177/001872675400700202

Fiske, S., Kenny, D., \& Taylor, S. (1982). Structural models for the mediation of salience effects on attribution.

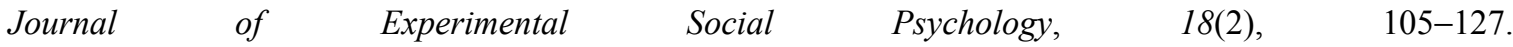
https://doi.org/10.1016/0022-1031(82)90046-4

Fiske, S. T., \& Taylor, S. E. (1991). Social cognition. McGraw-Hill.

Grabe, S., Ward, L. M., \& Hyde, J. S. (2008). The role of the media in body image concerns among women: A meta-analysis of experimental and correlational studies. Psychological Bulletin, 134(3), 460-476. https://doi.org/10.1037/0033-2909.134.3.460

Haboush, A., Warren, C. S., \& Benuto, L. (2012). Beauty, Ethnicity, and Age: Does Internalization of Mainstream Media Ideals Influence Attitudes Towards Older Adults? Sex Roles, 66, 668-676. https://doi.org/10.1007/s11199-011-0102-6

Häfner, M. (2004). How Dissimilar Others May Still Resemble the Self: Assimilation and Contrast after Social Comparison. J Consum Psychol. https://doi.org/10.1207/s15327663jcp1401\&2_21

Halliwell, E., \& Dittmar, H. (2004). Does Size Matter? The Impact of Model's Body Size on Women's Body-Focused Anxiety and Advertising Effectiveness. Journal of Social and Clinical Psychology, 23(1). https://doi.org/10.1521/jscp.23.1.104.26989

Hüttl, V., \& Gierl, H. (2012). Effects of Slim and Heavy Advertising Models on Appearance, Self-Esteem and Product Evaluations. Advances in Advertising Research, 3, 29-42 https://doi.org/10.1007/978-3-8349-4291-3_3

Ieva, M., Ziliani, C., Ziliani, C., Gázquez-Abad, J. C., \& D’Attoma, I. (2017). Online versus Offline Promotional Communication: Evaluating the Effect of Medium on Customer Response. Journal of Advertising Research, 58(3). https://doi.org/10.2501/JAR-2017-040

Janssen, D. M., \& Paas, L. J. (2014). Moderately thin advertising models are optimal, most of the time: Moderating the quadratic effect of model body size on ad attitude by fashion leadership. Marketing Letters, 
25, 167-177. https://doi.org/10.1007/s11002-013-9249-y

Johar, G. V., Maheswaran, D., \& Peracchio, L. A. (2006). MAPping the Frontiers: Theoretical Advances in Consumer Research on Memory, Affect, and Persuasion. Journal of Consumer Research, 33(1), 139-149. https://doi.org/10.1086/500493

Kooli, C., Al Habsi, A., \& Abadli, R. (2018). Celebrity Endorsement and Its Effect: Arabic World Perspectives. International Journal of Advanced Research, 6(2), 182-188. https://doi.org/10.21474/IJAR01/6426

Lennon, S. J. (1992). Categorization as a Function of Body Type. Clothing and Textiles Research Journal, 10(2). https://doi.org/10.1177/0887302X9201000203

Liu, X., Hu, M. Y., \& Grimm, P. E. (2010). Affect transfer in brand extensions: The role of expectancy and relevancy. Journal of Product \& Brand Management, 19(5). https://doi.org/10.1108/10610421011068559

Mitchell, A., \& Olson, J. (1981). Are Product Attribute Beliefs the Only Mediator of Advertising Effects on Brand Attitude? Journal of Marketing Research, 18(3), 318-332. https://doi.org/10.2307/3150973

Monro, F., \& Huon, G. (2005). Media-portrayed idealized images, body shame, and appearance anxiety. International Journal of Eating Disorders, 38(1), 85-90. https://doi.org/10.1002/eat.20153

Owen, P., \& Laurel - Seller, E. (2006). Weight and Shape Ideals: Thin Is Dangerously In. Journal of Applied Social Psychology, 30(5), 979-990. https://doi.org/10.1111/j.1559-1816.2000.tb02506.x

Petty, R., \& Cacioppo, J. (1986). The Elaboration Likelihood Model of Persuasion. In Communication and Persuasion (pp. 1-24). https://doi.org/10.1007/978-1-4612-4964-1_1

Roberts, J. A., \& Roberts, C. (2015). Does Thin Always Sell? The Moderating Role of Thin Ideal Internalization on Advertising Effectiveness. Atlantic Marking Journal, 4(1).

Shoenberger, H., Kim, E., \& Johnson, E. (2019). \#BeingReal about Instagram Ad Models: The Effects of Perceived Authenticity: How Image Modification of Female Body Size Alters Advertising Attitude and Buying Intention. Journal of Advertising Research, 60(2). https://doi.org/10.2501/JAR-2019-035

Singer, T. L., Alexander, P., \& Berkowitz, L. (2017). Effects of Processing Time on Comprehension and Calibration in Print and Digital Mediums. The Journal of Experimental Education, 87(1), 101-115. https://doi.org/10.1080/00220973.2017.1411877

Solomon, M. R. (2015). Consumer Behavior: Buying, Having, and Being. Pearson.

Stewart, K., Kammer-Kerwick, M., Koh, H., \& Cunningham, I. (2018). Examining digital advertising using an affect transfer hypothesis. Journal of Research in Interactive Marketing, 12(2). https://doi.org/10.1108/JRIM-07-2017-0053

\section{Copyrights}

Copyright for this article is retained by the author, with first publication rights granted to the journal.

This is an open-access article distributed under the terms and conditions of the Creative Commons Attribution license (http://creativecommons.org/licenses/by/4.0/). 